\title{
Comunicación

\section{Esperando a los bárbaros: \\ leyendas urbanas, rumores e imaginarios sobre la violencia en las ciudades}

\author{
FRANCISCO JAVIER CORTAZAR RODRÍGUEZ1
}

Las leyendas urbanas y los rumores que circulan a través de los medios de comunicación, correos electrónicos y páginas web tratan de una amplia diversidad de temas. En este trabajo nos centramos en las que tienen por temática la violencia urbana, en particular el tema de los maniáticos urbanos, las pandillas hiperviolentas, las películas que tratan de la muerte en directo, el terrorista y el lobo con piel de cordero. Al analizarlos accedemos a significados profundos e imaginarios colectivos sobre la violencia, los peligros de la vida moderna y los estereotipos sobre los "otros".

PALABRAS CLAVE: leyendas urbanas, rumores, imaginarios, violencia urbana.
The rumors and urban legends that we can find in the internet, e-mail and the media are about a great variety of topics. In this paper we focus in some rumors and urban legends which topics are based on urban violence such as the urban maniac, the very violent gangs, the snuff movies, the terrorist and the wolf wear lambskins. The analysis of rumors and legends help us to understand collective imaginaries and mutual representations in both violence and the risks of modern life.

KEY WORDS: urban legends, rumors, imaginary, urban violence.

1 Universidad de Guadalajara.

Correo electrónico: fcovier@yahoo.com 


\section{INTRODUCCIÓN}

En este trabajo nos proponemos mostrar que el estudio de las leyendas urbanas y rumores nos permite el acceso a una gran cantidad de significados a través de los cuales se plasman angustias, miedos, esperanzas e imaginarios de las sociedades contemporáneas, entre ellas la violencia. Para nuestra exposición nos centraremos en ejemplos recientes que han circulado en México y América Latina en los últimos cinco años y que han sido difundidos a través del correo electrónico, páginas web y medios de comunicación. ${ }^{2}$ Considerando que el tema de la inseguridad ciudadana ha ganado espacio en la agenda de gobiernos, medios de comunicación y grupos sociales: ¿cómo desarrollamos explicaciones que nos ayuden a sobrellevar la angustia?, ¿a quienes señalamos como sospechosos de actos antisociales y de riesgo para la comunidad?, ¿qué tan novedosas resultan estas explicaciones? Intentaremos contestar estas preguntas sirviéndonos de rumores y leyendas urbanas que tienen a la violencia citadina como elemento común. Debido a su gran diversidad y número nos concentraremos sólo en unos pocos temas y ejemplos.

\section{¿QUÉ SON LAS LEYENDAS URBANAS Y LOS RUMORES?}

Agujas infectadas de SIDA en los asientos de los cines, jóvenes varones a los que les han robado los riñones después de haber conocido a una atractiva mujer en un bar, cocodrilos en las alcantarillas, gente a la que le roban su línea de teléfono después de marcar ciertas teclas del mismo, aprendices de pandilleros que circulan en auto por la noche con los faros apagados y asesinan a todo aquel que les hace el cambio de luces, calcomanías con droga que se venden a los niños en las afueras de las escuelas, los peligros de la Coca Cola, aviones que se roban la lluvia, jovencitas que desaparecen en los probadores de tiendas de ropa, canciones de rock que contienen mensajes satánicos o los padecimientos de cáncer por usar teléfonos celulares: ¿qué tienen en común todas estas historias? Su común denominador es que se trata de "leyendas urbanas y rumores".

2 Este trabajo es un avance del proyecto "Imaginarios, rumores y leyendas urbanas". 
Las leyendas urbanas son esas historias extravagantes, pero creíbles, que pasan de boca en boca como si fueran verdaderas. Profundamente arraigadas en nuestra cultura, estas coincidencias increíbles, accidentes absurdos y delitos rocambolescos beben del inagotable ingenio de la tradición oral. Una de sus principales características es que suelen iniciar por la conocida frase: "Al amigo de un amigo...", pues suelen ser narradas como si el protagonista de la historia fuera alguien conocido de primera mano por el narrador, pero siempre resulta que este, a su vez, la escuchó de alguien más.

Las leyendas urbanas, o "leyendas contemporáneas", que circulan en las sociedades modernas, se encuentran ancladas en la tradición oral y el folclore. Son una actualización de los mitos, cuentos, leyendas populares $\mathrm{y}$ rumores que circulaban en las sociedades premodernas. Al diseccionarlas accedemos a las creencias, rituales, ceremonias, costumbres y acciones que las sociedades festejan, censuran, castigan o temen. Representan el bagaje cultural de la gente común a través de las cuales se aprenden lecciones morales que sancionan el bien y el mal. En cierta forma son "historias ejemplares" que enseñan y educan de forma didáctica, estética, emocional o recreativa sobre las normas sociales de convivencia y nos muestran cómo ha evolucionado la sociedad a través del tiempo, por ejemplo, advirtiéndonos de forma metafórica o velada los peligros de las nuevas tecnologías (como cuando hablamos de los peligros que encierran los teléfonos celulares, las sartenes de teflón, los hornos de microondas o internet), de los riesgos de la vida moderna (al hablar del robo de órganos, de la leyenda del "Bienvenido al mundo del SIDA" o las snuff movies, películas que pretenden filmar la muerte en directo), del regreso de los animales salvajes a la ciudad (los ya referidos cocodrilos en las alcantarillas, las arañas que ponen sus huevos en humanos o los racimos de plátanos que alojan serpientes o arañas venenosas), o la presencia de lo sobrenatural y lo fantástico en la modernidad (fantasmas en fotografias, las cadenas de cartas que prometen riqueza y amor con sólo reenviarlas o la presencia de animales fabulosos como el Chupacabras) (Cortazar, 2005).

Todas ellas cumplen funciones sociales y simbólicas específicas, como la transmisión de una información que juzgamos importante, la revelación de un problema social real y actual, la enseñanza de un mensaje moral o como reactivación de viejos motivos simbólicos. 
Las leyendas urbanas y los rumores, que son dos géneros vecinos y muchas veces se confunden al tomar elementos el uno del otro, tienen grosso modo características que, analíticamente, nos permiten diferenciarlas. El rumor suele ser un fenómeno de corta duración, efímero en el tiempo, que se mueve a través de redes sociales delimitadas, sigue circuitos específicos, suele transmitirse de boca en boca y conoce una gran cantidad de variaciones, añadidos y distorsiones a medida que se transmite. Su fuente suele ser anónima, hace circular información que no se puede citar oficialmente, especula sobre el comportamiento de otras personas, le confiere explicaciones posibles a actos y acontecimientos, sirve como forma de anticipación a los eventos y ayuda a hacer explícitos las reglas de convivencia entre la gente. Sirve como medio para canalizar angustias y construye un espacio común de relajación, de construcción de alianzas y contribuye a desacralizar a los poderosos para igualarlos a los demás, así como a especular sobre la conducta u opiniones de los iguales (Renard, 1999; Kapferer, 1995).

Por su parte, la leyenda urbana, o contemporánea, suele tener una vida más larga y estable, cuenta con una estructura general y muchas variantes locales que van cambiando de acuerdo con las circunstancias, conoce periodos de amplia difusión y momentos de letargo, al cabo de algún tiempo (generalmente años) "despierta" y se pone en circulación nuevamente. Es un medio que sirve para explicitar angustias sociales colectivas, problemas latentes en la sociedad y sirve de medio de educación moral o estético. Suelen constituir historias ejemplares, pues mediante su narración pretenden educar y advertir sobre los riesgos de la convivencia en sociedad, son narradas como auténticas y sucedidas al amigo de un amigo, presentan cierta vena de moralidad al sancionar el bien y el mal, lo correcto y lo incorrecto, de ahí que las leyendas urbanas tengan tanto éxito entre los adolescentes, pues son una parte importante que les ayuda a su formación como adultos (idem). En ocasiones un rumor persistente puede convertirse en leyenda contemporánea y, viceversa, esta, al simplificarse, se convierte en un rumor. Los rumores y las leyendas urbanas suelen ser ampliamente difundidas por los medios de comunicación que, en muchas ocasiones, los toman por ciertos. En los últimos años ambas han conocido un resurgimiento y puesta al día gracias a la difusión creciente de internet, los teléfonos celulares, la literatura, el cine y la televisión. 
Cuando hablamos de cultura popular no nos referimos necesariamente a la cultura de las clases menos favorecidas, sino a aquella que es compartida por el grueso de la población, en buena parte gracias a los contenidos de las industrias culturales. Para algunos autores la cultura popular contemporánea es una cultura ampliamente mediatizada, transclasista, donde los grandes perdedores han sido las tradiciones de las clases socioeconómicas empobrecidas, así como las de las clases altas, sobre todo la cultura humanista, en franco retroceso (Furió, 2000).

Siempre han existido los cuentos, leyendas, rumores, chismes y demás manifestaciones populares como medio de explicación de los acontecimientos de la vida cotidiana, pero no es sino hasta la Segunda Guerra Mundial que el rumor se convirtió en un arma de guerra psicológica para causar confusión y desaliento entre las filas enemigas y poblaciones de ambos bandos (Fussell, 2003). Más tarde, durante las décadas de 1970 y 1980 , el estudio de las leyendas contemporáneas y los rumores logra cierta autonomía como campo de estudio gracias a los aportes de diversas disciplinas: sociología, psicología, folclore, antropología, psicoanálisis y lingüística. Con la celebración regular de congresos internacionales, publicaciones, confrontación de métodos de análisis y terminología, el campo ha logrado cierta respetabilidad y presencia académica, con más fortuna en algunos países que en otros. En el mundo anglosajón y escandinavo tiene una gran presencia, mientras que en la Europa latina comienzan a ganar terreno y en América Latina apenas se está emprendiendo su estudio (Zires, 2001), de ahí la escasez de publicaciones en español. Esperamos que el presente trabajo contribuya a resolver una pequeña parte del problema.

Una última aclaración respecto al uso del concepto "leyenda urbana”: algunos están en desacuerdo con el mismo, pues describiría aquellas narraciones que acontecen en la ciudad y dejaría de lado los relatos que suceden en el mundo rural, además de que se considera que el término es una traducción directa del inglés urban legend. Para incluir las narraciones y hechos que se presentan en el mundo rural, consideran que el mejor término sería el de "leyenda contemporánea ", lo que borraría el city-centrismo del término anglosajón (Renard, 1999). Sin embrago, leyenda urbana es un término ampliamente aceptado y relativamente 
popularizado, por lo que en este trabajo emplearemos ambos como sinónimos, aunque nuestra preferencia va por el segundo término.

Por otra parte empleamos el concepto de imaginario en el sentido de que lo entendemos como parte constitutiva del mundo intersubjetivo (junto a lo real y lo simbólico), capaz de crear imágenes dentro del orden de la cultura y el lenguaje (lo simbólico) y que encuentra su continuidad dentro del orden social (lo real) (Payne, 2002: 399). Es decir, entenderemos el imaginario social como parte del capital cultural de un grupo social en un momento dado. Para Castoriadis, el imaginario social es lo que mantiene unida a una sociedad y le otorga su singularidad y sus diferencias, al tiempo que sus significaciones orientan y dirigen el comportamiento social. Castoriadis considera que lo imaginario es una creación continua de figuras, formas e imágenes que ordenan y dan sentido a lo real y a la racionalidad y su interiorización, en gran parte inconsciente, dota de sentido a los modos de pensamiento y acción, a las normas, valores e identidades de los individuos (Castoriadis, 1975).

Este trabajo se centra en rumores y leyendas contemporáneas que hablan de la violencia urbana y las formas en cómo ella es explicada y entendida por la gente común. Sin embargo, no pretendemos abarcar todo el problema ni profundizar en él, ante todo deseamos abarcar algunos fenómenos que consideramos representativos y de actualidad, como el caso de las pandillas hiperviolentas, el miedo al contagio de enfermedades como el SIDA, el terrorismo o los amables vecinos que, bajo la piel de cordero, esconden al lobo feroz devorador de jovencitas. También hemos dedicado un apartado a un fenómeno poco estudiado, no probado de forma convincente hasta hoy en día, pero que persiste como real en la creencia colectiva, nos referimos a las snuff movies, esas películas que ponen en escena la muerte real de una persona. Otros temas han sido dejados por lo pronto de lado, entre ellos las leyendas sobre el robo de niños, el secuestro de mujeres jóvenes, el robo de órganos y los peligros alimentarios. En todos los ejemplos citados en el presente trabajo hemos conservado la grafía original (sintaxis, ortografía, signos de puntuación) para que el lector observe las características que esos mensajes tienen y que serán señaladas más adelante. Tales características de redacción son claves, pues contribuyen a crear su efecto de verdad. 
Los ejemplos seleccionados no pretenden la exhaustividad, sino ser ilustrativos de la amplia variedad de leyendas a las que pertenecen sus temáticas. Los hemos seleccionado a partir de dos criterios básicos: ser recientes y cercanos en lo geográfico. Después referenciamos otros ejemplos en los que se insertan dichos ejemplos, es decir, en corpus más amplios, muchos de los cuales el lector puede consultar a través de la bibliografía y en los sitios especializados existentes en internet citados al final del presente trabajo.

\section{LA SOCIEDAD Y SUS ENEMIGOS}

La expresión "violencia urbana" designa un fenómeno que caracteriza a todas las sociedades donde la ciudad se ha convertido en el lugar de vida mayoritario. El fuerte control social del grupo sobre el individuo de las comunidades rurales ha cedido su lugar al anonimato y a una mayor trasgresión de las normas sociales de las sociedades urbanas.

Más allá de los índices de violencia real nos ocuparemos de la violencia imaginada. El extranjero, no sólo de otro país sino del grupo social, es designado como el chivo expiatorio de las agresiones que sufren las víctimas. El espacio entre las estadísticas de la delincuencia real y los sentimientos de inseguridad son el terreno donde se desarrolla el imaginario de la violencia, expresado a través de leyendas urbanas y rumores.

Esos relatos expresan el miedo a la violencia, la angustia de ser agredido, la variedad de personajes que pueden hacernos mal o las innumerables situaciones en que podemos rozar la muerte: las agujas infectadas de SIDA en los asientos de los cines, los ataques terroristas en las grandes ciudades, las pandillas hiperviolentas o los atacantes disfrazados de amables vecinos. La existencia de las llamadas snuff movies nos permitirán evocar la obsesión contemporánea de crímenes sexuales y la muerte como espectáculo. La mayoría de los ejemplos aquí reproducidos han circulado de forma amplia a través de los correos electrónicos, internet y algunos medios de comunicación, como la prensa y la televisión.

\section{Las agujas infectadas de SIDA en los cines}

El SIDA como enfermedad ha despertado amplios comentarios sociales sobre sus orígenes, causas y efectos, de forma que se ha constituido, 
junto al cáncer, en la enfermedad que caracteriza al siglo XX, tal y como lo fueron en su tiempo otras enfermedades: la lepra en los tiempos bíblicos, la peste en la Europa de la Edad Media o la tuberculosis durante los siglos XVIII y XIX. Esas enfermedades, además de haber marcado una época también lo han hecho con los afectados, pues les inocula un sentimiento de estigma social: pena, compasión, vulnerabilidad e incluso vergüenza y culpabilidad (Sontag, 1989).

La leyenda contemporánea sobre las agujas infectadas de SIDA en los asientos de los cines ha circulado en numerosos países al menos desde finales de los años ochenta y principios de los años noventa, acompañando los rumores y creencias sobre la nueva enfermedad. Las numerosas versiones que circulan a través de los correos electrónicos, desde mediados de los años noventa, tienen una serie de elementos comunes: el mensaje es redactado de forma dramática, combina frases escritas con mayúsculas y signos de puntuación que le confieren mayor urgencia, suelen contener numerosas faltas de ortografía y sintaxis, presentan variedades locales citando lugares y hechos reconocibles para cada lector y suelen decir que los hechos narrados han sido confirmados por las autoridades. Con frecuencia el relato suele ir firmado por una fuente que agrega sus propios datos, lo que contribuye a su verosimilitud.

Esto pasó en Guadalajara. Un incidente ocurrió cuando una amiga de un trabajador de Femsa, fue al cine y se sentó en una silla, ella sintió que algo la estaba pinchando. Cuando se levantó para ver de qué se trataba vio que se trataba de una aguja acompañada de una nota que decía: "Bienvenida al mundo real, ya eres VIH Positivo". El Centro de Control de Enfermedades reporta numerosos casos similares en muchas otras ciudades. Todas las agujas encontradas SON positivas de VIH.

También en los teléfonos públicos consumidores de drogas están poniendo agujas usadas en el orificio donde recibes el cambio para que las personas, al buscar el cambio o ver si alguien a dejado algo, sean infectadas con HEPATITITIS B, SIDA Y OTRAS ENFERMEDADES.

La forma mas segura de hacerlo NO ES PALPANDO CON SU MANO para ver si siente la aguja, al menos mueva el asiento varias veces para ver si hay algo.

FIJESE MUY BIEN. 
Igualmente les pedimos que pasen este mensaje a todos los miembros de su familia y a sus conocidos. La información mencionada es confirmada por el departamento de policía. Hay que reenviar esta información al mayor número de personas posible. ES MUY IMPORTANTE!!!!!!!!!! Este mensaje es un servicio social, coopere con su distribución y CUIDENSE.

Gracias!!!!!!!!!!

Una característica adicional de las leyendas urbanas y rumores que circulan a través de Internet es que suelen ser traducciones poco afortunadas de otros idiomas, generalmente del inglés, por lo que hay citas de instituciones que no existen en el país o región a la que hacen alusión. En este caso, algunos mensajes circulaban citando un supuesto "Centro de Control de Desastres", traducción mal hecha del "Center of Disease Control", pues disease equivale en español a "enfermedades", no "desastres".

A través del ejemplo citado más arriba podemos intuir la fuerza de los mensajes de alerta; su poder de persuasión hace que, sin reflexionar ni releer, seamos seducidos, convencidos y lo retransmitamos. Los usuarios con ciertos conocimientos científicos saben que el virus del SIDA muere en poco tiempo al aire libre, pero no son ellos los que predominan en la era de internet, sino usuarios comunes y corrientes. Por otra parte, los desmentidos y correcciones a estos mensajes no suelen despertar interés ni circulan con profusión entre la gente. Siempre es más emocionante sentir que vivimos al filo del peligro añadiéndole sal y pimienta a nuestras acciones más anodinas.

El mensaje despierta en nosotros el horror ante la sola idea de ser contaminados de VIH-SIDA y el miedo a las agujas que despierta en mucha gente. Desde los leyendas contemporáneas de los "maniáticos urbanos" a la "trata de blancas" del siglo XX, las agujas han jugado un papel que provoca cierta repulsión social. Para Veronique CampionVincent y Jean-Bruno Renard (2002) las jeringas han tomado el lugar de las puntas de las flechas, agujas de cocer y astillas envenenadas de los cuentos populares de antaño, como en Blancanieves y La Bella Durmiente del bosque.

El mensaje "Usted ha sido contaminado de SIDA", que acompaña a las agujas en los cines, también nos recuerda a la leyenda urbana del viajero solitario que ha conocido a una joven en un bar y que al día si- 
guiente, después de pasar la noche con ella, encuentra escrito con lápiz labial en el espejo: "Bienvenido al mundo del SIDA".

Otra variante de la historia dice que en algunas áreas infantiles de los restaurantes McDonald's se han presentado casos de niños que al estar jugando entre las pelotas se pinchan con agujas que gente desconocida ha metido ahí. Incluso, en algunos casos, se sugiere la complicidad de la compañía en esta actitud criminal, pues se niega a admitirlo públicamente para no perder clientes.

Casos y hechos aislados y reales se mezclan aquí con el imaginario sobre la violencia irracional en las ciudades que nos dicen que todos somos víctimas potenciales de una agresión que transformaría para siempre nuestra vida: “¿Por qué a mí?”. Antecedentes de ataques espontáneos con agujas, navajas o cuchillos a peatones se registran en numerosos lugares a través de las épocas. Así, durante mucho tiempo, ha circulado la leyenda urbana según la cual en las ciudades circulan autos o ciclistas que pican a sus víctimas, generalmente mujeres, en el trasero si caminan por el lado del arroyo de las aceras.

Un caso muy semejante al escenario que describe la sabiduría popular sucedió en Mar del Plata, Argentina, en mayo de 2005, según cita el diario El Clarín. ${ }^{3}$ Según esa nota un joven con serios problemas psicológicos fue arrestado por la policía por agredir a mujeres en la vía pública picándolas con jeringas, clavos o cúters. Los ataques provocaron una histeria colectiva entre las jóvenes de la localidad. Hechos como este hacen creíbles las numerosas narraciones contemporáneas que hablan de la existencia de agresores armados de agujas o navajas. Al mismo tiempo nos invitan a debatir entre las conexiones entre la realidad y la ficción: ¿el agresor de Mar del Plata se basó en alguna leyenda urbana o fue mera coincidencia?

\section{El terrorista agradecido}

Después de los ataques terroristas del 11 de septiembre de 2001 en Estados Unidos, circularon con profusión numerosos rumores sobre posibles nuevos ataques, alarmas y "explicaciones" sobre el acontecimiento.

3 El Clarín (10 de mayo de 2005) "Detienen a joven acusado de agredir a mujeres con jeringas". 
Las imágenes y leyendas contemporáneas que circularon entonces iban desde la famosa fotografía de un supuesto turista tomada sobre una de las torres poco antes del impacto de un avión contra el edificio, la cara del Diablo saliendo de entre el humo, el hasta ahora persistente rumor de que nunca se estrelló ningún avión contra el edificio del Pentágono, sino que se trataba en realidad de un misil, el rumor de que los servicios de inteligencia israelíes avisaron a cuatro mil judíos que trabajaban en el WTC de no acudir ese día a trabajar y muchos otros más. Trataremos aquí sólo uno de esos casos. Se trata de la leyenda del "terrorista agradecido" (o "compatizante"), como se le ha dado en llamar.

En una de las tantas versiones que corrieron en esos días se hablaba de un hombre, tipo árabe, al que le faltan unas monedas para pagar sus compras en un supermercado. Siempre se citan diferentes nombres de ciudades, aunque normalmente se trataba de las más representativas de los Estados Unidos: Nueva York, Los Ángeles, Washington, Chicago, etc. Según el mensaje, una mujer, formada en la fila de la caja atrás de él, se ofrece a pagar el faltante, que no es mucho. Una vez en el estacionamiento, la mujer es abordada por el hombre que le dice: "Un favor se paga con otro favor, no tome el metro el día de mañana". La mujer, inquieta, decide ir a la policía a contar lo sucedido. Después de escuchar su historia, los policías le muestran las fotografías de los terroristas conocidos y ella identifica al hombre entre ellos.

En cada país o ciudad que ha conocido atentados terroristas en el pasado, esta historia circuló con profusión y, como siempre, adoptando variedades locales. En París (que sufrió un ataque terrorista en su red de transporte público subterránea en julio de 1995), la historia situaba los hechos en el metro de la ciudad y se trataba de un hombre de aspecto árabe que en un descuido dejaba caer su billetera, la cual le era devuelta por una mujer. El mismo mensaje circuló en Londres por las mismas fechas, siempre relatado como "Me lo contó un muy amigo de la chica a la que le pasaron los hechos". En ese mensaje se decía que todo ocurrió en Hyde Park y agregaba que el hombre, además de rasgos árabes, parecía militar y muy seguro de lo que hablaba. Esta observación sobre el aire marcial del hombre despierta el imaginario social que circula sobre los militares: gente acostumbrada a obedecer órdenes sin chistar, desprovistos de alma y razón, sin miedo en la mirada. 
Otro tanto ha ocurrido en Madrid después de los ataques terroristas del 11 de marzo de 2004, cuando se dispararon los rumores sobre nuevos atentados. Uno de ellos es una actualización del "terrorista agradecido". Se trata de variantes en las que se repiten los motivos: un hombre de aspecto árabe, un ciudadano que ha realizado una acción desinteresada y la advertencia de un atentado próximo. En una versión se habla de posibles atentados en centros comerciales ${ }^{4} \mathrm{y}$ en otra se advierte a la gente no beber Coca Cola: 5

\section{Mensaje: Coca Cola}

Ya lo he enviado a la gente, pasadlo vosotras.

ME HA LLEGAdo EL SIGUIENTE RUMOR. NO SÉ LA PARTE DE VERdAD QUE PUEDA TENER, PERO POR SI ACASO... Me han contando que hace unos días, después del atentado, se presentó en una peluquería un hombre de raza árabe que llevaba un maletín en la mano. Después de cortarse el pelo se marchó y se dejó olvidado el maletín. Los dueños de lapeluquería, intrigados, abrieron el maletín y lo encontraron lleno de dinero. No avisaron a la policía y, al rato, volvió el árabe a por su maleta.

Les preguntó si habían avisado a la policía, le dijeron que no y entonces les dijo: "LES AGRADEZCO MUCHO QUE NO HAYAN LLAMADO A LA POLICÍA, EN AGRADECIMIENTO LES VOY A DAR UN CONSEJO: NO BEBAN COCA COLA A PARTIR DEL 4 DE ABRIL"

No sé nada más, pero no puedo dejar de comunicarlo. LEERLO, Y PASARLO A LOS CONOCIDOS.

El hecho de mencionar precisamente el famoso refresco de cola nos recuerda las numerosas leyendas que circulan sobre ella (que si es adictiva, que si puede disolver un pedazo de carne o un diente al cabo

4 “La policía califica de 'falso' el mensaje que alerta de un supuesto atentado en Madrid el 21 de abril", elmundo.es, edición electrónica de El Mundo (22 de abril de 2004) (http://www.elmundo.es/elmundo/2004/04/21/enespecial/1082537126.html/2004/04/21/ciencia/1082524495.html) [1 de junio 2004].

5 "La leyenda del terrorista agradecido": http://www.rompecadenas.com.ar/ hoaxes/terrorista.htm [1 de junio de 2004]. 
de un par de días, que si es un excelente antioxidante, que si sólo dos personas en el mundo conocen la formula supersecreta de la bebida, que si un excelente anticonceptivo, incluso que fue inventado como medio esterilizante para controlar a la población negra, etc.). Hay tantas leyendas urbanas que abrevan de la negra bebida para alimentar su negra leyenda, que incluso se agrupan bajo un subtema especial: Coke-lore (relatos populares sobre la Coca Cola) (Brunvand, 2002a: 77), y por supuesto la toman como blanco no sólo por su popularidad sino también por ser considerada como una bebida "imperialista" que destruye los valores y tradiciones culinarias de las comunidades donde se inserta. Hablamos de una bebida emblemática del American way of life y de la modernidad.

Tanto en la primera versión citada aquí sobre el terrorista al que le faltan unas monedas en el supermercado como en la precedente, donde lo que se rescata es un maletín lleno de dinero, así como el intercambio de favores, constituyen por su significado elementos mágicos, que explicaremos unas líneas más adelante una vez que hayamos visto otros elementos importantes.

En otro ejemplo, que circuló después del 11 de septiembre de 2001, esta vez en Buenos Aires, se hablaba otra vez de nuevos atentados en centros comerciales y tiendas departamentales. La presencia del extranjero de origen árabe es recurrente:

\section{Alerta de un Atentado}

Nosecuantodeciertopuedehaberenestoperonopuedodejardeinformarselospor lasdudas,porlomenosquequedeencadaunodenosotrosladecisiondecreerloono. Lo unico que puedo decir es que la señora que me manda el mensaje, es una persona mayor y de mucha confianza, si es una broma no salio de ella. Besos, y espero que solo sea una broma pesada.

Hola!

Una amiga me contó algo que puede parecer un poco raro. Una amiga de ella conoce a una Argentina, casada con un Musulman, que vive en EE. UU. Parece que él la abandono y volvio a su pais, pero dejo una carta para ella en que le advirtio que no debia ir a Nueva York el 11 de Septiembre por ninguna razon. Ahora le hizo llegar una carta en la cual le dice que ella debe advertir a su 
familia en Argentina que se alejan de los shoppings y supermercados grandes este fin de semana que viene. Ojala que no pase nada, pero tal vez seria mejor que estemos prevenidos.

Un beso, Daphne.

Como es usual en este tipo de cadenas de cartas, las fechas a las que hacen alusión son indeterminadas, de forma que "este fin de semana" podría ser aplicado a cualquier fin de semana de no importa qué mes y año. Por otra parte, no es de extrañar que dicha versión haya circulado en Buenos Aires, pues la ciudad ya había sufrido un ataque, hasta ahora no del todo esclarecido, en la sede de la Asociación Mutual Judía (AMIA) en 1995. La siguiente es una variante que circuló en Barcelona en marzo de 2002, antes de los atentados de Madrid de marzo de 2004:

Hola a todos,

Os quiero avisar de un posible atentado.

Algunos creeréis que es broma, pero no lo es. Os explico.

El otro dia, una compañera de vivienda de una compañera de universidad de Anabel (mi novia), fue al supermercado a comprar. Delante tenía a una persona árabe, muy bien trajeado. Resultó, que le falto poco mas de 1 euro para la compra, y esta chica se ofreció y se lo dio. El árabe agradecido, le dijo que se lo daría, y ella dijo que no hacia falta, que solo era un euro y algo mas. El siguió insistiendo, y ella le quito la menor importancia, y le dijo que "hoy por ti, mañana por mi”. El árabe acto seguido le dijo : "te lo agradezco mucho, y por ello te voy a dar un consejo. El día 16 no estés en Barcelona porque habrá un atentado"

Obviamente esta chica se fue directamente a la policía a contarlo, y tras mirar unas fotos, cual fue la sorpresa que estaba fichado, y resulta ser uno de la banda del Bin Laden.

Todo esto que os he dicho es cierto, y no es alguien que conoce a alguien, que conoce a alguien, y así... sino es una persona directa la que se lo contó a Anabel.

Resulta que el día 16 es el Barcelona-Madrid, y a parte, la Diagonal estará colapsada por las manifestaciones que hay por lo de la Globalización, conllevando a que este la Diagonal a petar. ¿Casualidad? no lo sé. Lo que sí 
que se es que es cierto que reconocieron a esta persona, y alguien directo a Anabel, no alguien de alguien...

Esta claro que yo no iré por la Diagonal ese día... puede ser cierto o falso lo del atentado, pero lo que si es cierto es que esta chica lo identificó en la comisaría. Os mando este e-mail para avisaros. Si queréis, enviarlo a quien queráis, yo por mi parte ya he dado el aviso y espero que no pase nada, pero si pasa, que nos pille lejos...

Salu2, Xavi.

p. d.: hacer un forward a quien creáis necesario, porque seguro que me dejo a gente.

Note el lector la recurrencia de lugares de paso, de anonimato, como lugar de encuentro con el terrorista y como blanco de los supuestos atentados: supermercados, centros comerciales, avenidas, estadios deportivos, estacionamientos. Lugares donde sólo estamos de paso y permanecemos solos entre la multitud.

Hasta antes del 11 de marzo de 2004, fecha de los atentados islamistas en Madrid, circulaban periódicamente avisos de actos terroristas que se cometerían en centros comerciales en fechas cercanas a las navidades. En esos rumores el enemigo no era identificado con un árabe sino con alguien de aspecto vasco, miembro de la banda terrorista ETA, puesto que el enemigo era ese en tal época:

Asunto: ETA EN LA NAVIDAD o IMPORTANTE NO ES UNA BROMA

\section{NO SE SI ES VERDAD PERO POR SI ACASO}

Facilitado por una buena amiga y compañera de mi Mujer.

Me ha llegado esto. No sé si será verdad o no, pero os lo mando.

LEEDLO PORQUE ESTO NO ES UNA BROMA.

Lo que os voy a contar no es una broma. La semana pasada, una amiga de mi madre estaba en la cola del CARREFOUR de Las Matas. Al chico que estaba pagando delante la faltaban 100 pelas y pidió que alguien le dejara las 100 pelas. Esta señora se las dio, y él se lo agradeció. Luego pagó ella. Salió y fue al coche a dejar las bolsas. Entonces vio acercarse al chico de la caja. Ella pensó que iba a pedirle más dinero. 
Sin embargo, cuando llegó a su altura, lo único que hizo fue darle las gracias sin parar, diciendo que pocas personas hacer una cosa así, bla bla bla... Se marchó, pero se detuvo y volvió hacia la señora. Le dijo: - Señora, en señal de mi agradecimiento, sólo le comento, por su seguridad, que no debe acercarse a grandes superficies [supermercados] de aquí a finales de diciembre. A continuación desapareció. Ella, extrañada, se fue a hablar con un amigo suyo que trabaja en la Dirección General de Seguridad. Le dijo que por qué no se pasaba un día por la comisaría a ver si lo reconocía en alguna lista. Fue y le mostraron mil álbumes de gente fichada.

LA SEÑORA, EN CINCO FOTOS DIFERENTES, RECONOCIÓ, SIN LA MENOR DUDA, AL CHICO DE LA CAJA COMO UNO DE LOS INTEGRANTES DEL COMANDO MADRID DE ETA.

INSISTO, ESTO NO ES NINGUNA BROMA: ETA PLANEAR PONER UNA BOMBA EN UNA GRAN SUPERFICIE DE MADRID ANTES DE NAVIDAD.

OS ESCRIBO ESTO COMO ADVERTENCIA (no es ninguna campaña contra grandes almacenes, lo juro por mi madre). CREO QUE DEBÉIS PASAR ESTO A CUANTA MÁS GENTE DE MADRID MEJOR.

A lo mejor, incluso de esta manera podríamos ayudar a localizar al etarra.

Es reiterativa la mención de supermercados y mujeres que son quienes reciben el aviso del terrorista. Sin embargo, en el mensaje anterior destaca la frase sobre "mil álbumes [con fotografías] de gente fichada", que por supuesto es una exageración, pero en el imaginario popular deja entrever la percepción que la gente tiene de la violencia urbana, de lo grande que está extendido "el mal" en la ciudad.

Historias como estas circularon en diversas ciudades de Inglaterra entre los años 1980-1990, pero en ellas se consignaba a un hombre de "acento irlandés" y fueron contemporáneas de los atentados terroristas perpetrados en el país por el ERI en aquella época. En Estados Unidos, después del 11 de septiembre, se decía que una joven recibió un correo electrónico de su novio afgano que le suplicaba no tomar ningún avión el 11 de septiembre y no ir a ningún centro comercial en el día de Halloween.

Las distintas narraciones sobre el terrorista agradecido muestran una estructura narrativa frecuente en las historias de predicción: la realización de un primer evento (un atentado terrorista en Buenos Aires, 
Madrid, Barcelona, Washington, Nueva York o Londres) hace creíble la realización de un segundo evento anunciado (un ataque en centros comerciales, supermercados o en el transporte colectivo). En el caso de Halloween en Estados Unidos, el 31 de octubre, aproxima esta anécdota a los relatos de terror y miedo que circulan en torno a esa fiesta, como las navajas de rasurar dentro de las manzanas y dulces que se les regalan a los niños o a los asesinatos cometidos por gente disfrazada, popularizados por películas americanas de miedo como Scream (1996), Halloween (1978) y otras.

No es extraño, pues, encontrar repetidos los mismos motivos: el terrorista, que según las circunstancias del momento es de origen irlandés, vasco o árabe, quien en agradecimiento por alguna acción desinteresada proporciona una información valiosa, la identificación sin lugar a dudas del maleante en los archivos de la policía, la información que es proporcionada por "el amigo de un amigo", que fue testigo de primera mano, y el "Corre la voz por si acaso", con el que concluyen todos los mensajes. Este tipo de rumores explotan un motivo ya presente en los relatos de guerra acerca del "enemigo amistoso", que a cambio de un servicio simpatiza y proporciona una información confidencial que salva numerosas vidas.

En general, esos relatos tienen por objetivo psicológico exorcizar la angustia de la gente frente a la agresión: por una parte se afirma que el enemigo es temible e implacable (las masacres reales o anunciadas) y, por la otra, que algunos de entre ellos son amistosos y pueden asegurar nuestra sobrevivencia. Por otra parte, al anunciar un evento futuro como algo cierto y definitivo, la gente retoma cierto control sobre su vida, control que creía haber perdido ante la amenaza fantasmagórica del terrorismo y el discurso securitario de los estados nacionales.

El motivo del dinero (el dinero del supermercado, la billetera en el metro, el maletín olvidado) reactiva motivos simbólicos antiguos. En cierta forma el dinero es intercambiado por una información vital, una recompensa que nos protegerá de un desastre inminente, frecuentemente se trata de una recompensa importante (la vida, la fortuna) a cambio de un pequeño servicio (dar un poco de comida, un préstamo, la reparación de una herramienta, información para escapar de una emboscada). Hay una gran desproporción entre regresar una billetera caída 
o la cantidad de moneda que hace falta para pagar unas compras en el supermercado, por una parte, y la información que permite salvar la vida y la de los seres próximos, por la otra.

En los cuentos folclóricos tradicionales el servicio es dado por un mortal a un ser fantástico en dificultades (dios, diablo, hada, la muerte, un gnomo) que le recompensa ampliamente concediéndole algo de sus poderes fantásticos. ${ }^{6}$ Los terroristas, que sí existen, ocupan ahora en el imaginario colectivo, sobre todo si son extranjeros, el lugar de los demonios y criaturas maléficas del más allá, al tiempo que se asemejan al lobo solitario que surge de lo profundo del bosque y regresa a su oscuridad para perderse en él y esperar el momento oportuno para atacar.

El hecho de que en el relato del terrorista agradecido la persona recompensada sea generalmente una mujer, no es casualidad. En las creencias y tradiciones populares es ella quien con frecuencia se encuentra en contacto con las fuerzas sobrenaturales y realiza las acciones caritativas. Los cuentos populares son paradigmáticos en ejemplos de mujeres de sentimientos nobles, altruistas y de gran belleza, tanto interior como exterior: Caperucita Roja, Blancanieves o Cenicienta.

\section{La pandilla hiperviolenta}

A finales de octubre de 2005, un mensaje que circulaba por las redes de correo electrónico de México, fue retomado ampliamente por los medios de comunicación nacionales. En ese mensaje se advertía de una pandilla llamada "Sangre":

La Dirección General de Asuntos Policiales Internacionales de la Agencia Federal de Investigación alertó a autoridades policíacas locales sobre acciones que supuestamente realizará una pandilla denominada "Sangre", de reciente aparición en el vecino país de Guatemala y que ataca a personas que se desplazan en vehículos de motor y quienes supuestamente les realizan el cambio de luces al encontrarlos de frente en la cinta asfáltica.

6 Por ejemplo, en la película mexicana Macario (1960), basada, a su vez, en una historia del escritor Bruno Traven, un indígena comparte su comida con la muerte; en agradecimiento, esta le regala un remedio con el que podrá curar cualquier enfermedad y hacerse rico. 
En el comunicado oficial se indica: "Si tu manejas de noche y ves un carro que no trae las luces prendidas, NO LE HAGA EL CAMBIO DE LUCES.

"Esto es un juego de iniciación de una pandilla que se hace llamar "Sangre", el juego consiste en los siguiente:

El nuevo prospecto a ser miembro de esta pandilla tiene que manejar con las luces apagadas y el primer carro que les haga el cambio de luces para avisarles que tienen las luces apagadas se convierte en su objetivo, el próximo paso es dar la vuelta y perseguir al carro que les hizo el cambio de luces para avisarles que las suyas estaban apagadas y MATAR a todos los pasajeros para poder ser aceptados en la pandilla.

Este próximo fin de semana será un fin de semana de iniciación de esta pandilla, por lo que se espera que los individuos que quieran ser miembros de esta pandilla andarán manejando con las luces apagadas buscando quien les haga el cambio de luces.

Esta leyenda urbana circula desde los primeros años de la década de 1980 en Estados Unidos. En su origen, el rumor decía que los integrantes de la pandilla Hell's Angels se iniciaban de esta manera; a mediados de los años ochenta la historia se contaba en Los Ángeles, pero se decía que la pandilla estaba integrada por minorías de negros y latinos. Con el desarrollo del fax, la historia se extendió y pasó a denominarse "Blood initiation weekend". En 1993 resurge el rumor con posteriores salidas a la luz en 1998 en Texas, y en 2004 en Inglaterra, prácticamente con las mismas características a como lo conoceríamos en México. La adaptación a nuestro contexto está dada por la mención a la Mara Salvatrucha, que representa un motivo de preocupación real de los cuerpos de seguridad del país, Centroamérica y del sur de Estados Unidos. ${ }^{7}$ Como dato curioso, en 1998 esta leyenda fue usada como historia para la película "Urband legend" (1998).

Hechos reales, inconexos entre sí, hacen creer en la existencia de la leyenda y otras semejantes. Por ejemplo, basándose en los enfrentamientos que protagonizaron algunos seguidores de ciertos equipos de futbol

7 El Universal (23 de octubre de 2005) "Alerta Interpol sobre pandilla 'Sangre"”; Público-Milenio (30 de octubre de 2005) “Ortega: la pandilla Sangre, 'mala broma' de Guatemala'. 
ingleses y escoceses en los años cincuenta, se hablaba entonces en Inglaterra de la Pandilla de las Navajas de Glasgow (Glasgow razors gang) que mutilaban a sus víctimas por medio de navajas de afeitar, haciéndoles cortes en las comisuras de los labios, dándoles en seguida un golpe en el estómago para hacer que gritaran y de esta forma desgarrar la herida. Las víctimas quedaban desfiguradas y la cicatriz semejaba a la sonrisa del Guasón, el célebre bandido popularizado por los comics y la película Batman (1989). En 1970 se hablaba de la pandilla de las chamarras verdes (o rojas) (Green/Reed Jacket Gangs) de Liverpool, que mutilaban a sus víctimas con navajas de rasurar y grababan en su rostro círculos o cruces. Para los años 1999-2000, en la región de la Bretaña francesa (noroeste del país), se habla de la Pandilla de las Gorras Blancas (Gang des Casquettes Blanches), que aterrorizaban a las adolescentes a la salida de la escuela. Según ese rumor los pandilleros les formulaban una pregunta sádica a las chicas: “¿Violación o mutilación?”. La mutilación consistía en hacerles la llamada "sonrisa del ángel", la rasgadura de las comisuras de los labios mencionada más arriba. También se decía que se trataba de pandillas formadas por "marselleses", ciudad reputada en Francia por estar habitada mayoritariamente por árabes.

En un plano psicoanalítico el rumor de la Pandilla Sangre abunda en elementos de agresividad masculina y destila testosterona: un grupo de hombres (que suele simbolizar la violación colectiva), un automóvil potente (en sus inicios se hablaba de los Hell's Angels, quienes usaban moto, otro símbolo fálico de poder), las características físicas y de vestuario de los integrantes (tatuados, de vestir llamativo y desafiante a las reglas sociales, con actitudes de menosprecio por los demás), objetos penetrantes (armas de fuego, cuchillos, navajas). En el caso de la mutilación de los labios, al separarlos por la fuerza, se trata de una violación simbólica.

La película Naranja mecánica (1971) es un claro ejemplo de esta simbología: sombreros de melón, bastones, protectores genitales, botas militares, pandillas que atracan y violan con lujo de violencia. El motivo de la mutilación de las comisuras fue empleado por el director Roland Joffé en el film La ciudad de la alegría (1992), donde una prostituta es castigada por medio de este método. Recientemente, la leyenda fue otra vez motivo de inspiración para ser escenificada en el cine, en 
la película El laberinto del fauno (2006), del mexicano Guillermo del Toro, donde una mujer escapa a su sádico vigilante no sin antes herirlo con un cuchillo; entre las heridas que le produce se encuentra "la sonrisa del Ángel".

Por otra parte, la leyenda contemporánea contiene elementos clasistas, racistas y xenofóbicos, pues primero culpa a los "extranjeros", generalmente provenientes de un país cuyos miembros son mal vistos por la sociedad en cuestión; en segundo lugar los tipifica como salvajes e incivilizados al denunciar la práctica de costumbres e iniciaciones tan bárbaras y, veladamente, los clasifica como de "otra" clase social, generalmente más baja, no educada, de barrios bajos, bajo el eufemismo de "pandilleros".

El motivo de la iniciación sangrienta es recurrente en numerosas leyendas populares de la Edad Media, en que se acusaba a los judíos de matar niños o mujeres jóvenes en sus ceremonias de iniciación; incluso esta leyenda circulaba ya en los tiempos de la antigua Roma, lo que confirmaría la continuidad de las leyendas tradicionales con las leyendas contemporáneas (Brunvand, 2002a: 37-38). También reaparece el motivo del lobo, el que esta vez ataca en grupo, en manada; rastrean, siguen y acorralan a sus víctimas, nuevamente mujeres jóvenes o familias que andan de paseo. De forma que la leyenda de la Pandilla Sangre contiene varios mensajes escondidos de amplio significado: el miedo a la agresión sexual, el miedo a la violencia ciega y el miedo al extranjero.

\section{Un lobo con piel de oveja}

Son frecuentes las leyendas contemporáneas y los rumores que hablan de gente amable, generalmente un hombre, que se acerca a alguna dama sola para ofrecer algún producto o prestar ayuda. En tales relatos, las verdaderas intenciones del lobo con disfraz de cordero son descubiertas gracias a que las víctimas presienten algo y logran escapar de la emboscada, como en el siguiente ejemplo:

Cuídate de los "limpiaparabrisas"

Les cuento lo que me pasó para que ustedes estén atentos, y le cuenten a sus amigos y familiares. 
El día 09 de marzo de 2004, aproximadamente a las 9 con 15 minutos de la noche, en el estacionamiento de la gasolinera de Circunvalación, se me acercó un señor humilde y bien amable de aproximadamente unos 45 a 50 años, estatura baja, canoso a ofrecerme un liquido "PULIDOR DE VIDRIOS".

Me dijo que le permitiera, que me iba a demostrar como funcionaba el liquido, procedió a vaciar parte del líquido en una esponja y comenzó a limpiar el parabrisas con un trapo y rápidamente hablaba de sus bondades, lo hizo en menos de $1 / 2$ minuto, posteriormente me dijo que viera cómo quedaba y me indico que no se veía lo suficientemente limpio porque la grasa acumulada en la parte interna del vidrio lo impedía, acto seguido, sin que yo lo autorizara o dijera algo al respecto, muy educada y sonrientemente introdujo por la ventana un trapo empapado en el "PULIDOR DE VIDRIOS” y empezó a limpiar el parabrisas por dentro y fue en ese momento cuando me sentí invadida, donde yo reaccioné y le dije que ya no siguiera y que sacara la mano.

Inmediatamente procedí a retirarme y aproximadamente a los 5 minutos se me empezó a dormir la cara, se me resecó la boca y empecé a temblar, lo que hacía que ya no pudiera manejar adecuadamente. Afortunadamente yo andaba con unos amigos, quienes andaban en dos vehículos por aparte; los llamé para que me esperaran porque yo me sentía mal, y así fue. Ellos se regresaron. Tenía aproximadamente 5 minutos de haberme parqueado y mis amigos estaban ya detrás de mi carro, cuando se acercó un vehículo con vidrios polarizados, pero al abrir la puerta de atrás pude divisar al Sr. Limpiador de vidrios adentro de él, preguntaron en qué podían ayudarme, pero al ver que no estaba sola y que éramos varios, cerraron la puerta rápidamente y se regresaron.

Gracias a Dios yo no estaba sola, porque si no, ahorita quien sabe en dónde estuviera.

Por favor CUENTEN esta forma de operar de estos desgraciados, quién sabe a quien más han tratado de secuestrar o robar.

Existen variantes de este rumor casi idénticos, solo cambian los lugares citados y las fechas. La relatora siempre es una mujer que es abordada por un hombre que aparenta ser amable y servicial; además, por sus años y apariencia, se intuye que no es peligroso. Un aspecto adicional está representado por las variantes lingüísticas de la región o país donde corre la versión, en este caso "limpiaparabrisas", "humilde", 
"bien amable", "yo andaba" o "ahorita", que son palabras más bien locales o nacionales de México, mientras que "pulidor de vidrios", "manejar adecuadamente", "dos vehículos por aparte" y "parqueado" son expresiones de diferente nivel lingüístico y regionales. Además, hay contradicciones que, en una segunda lectura, es posible detectar: "Vació el liquido en una esponja y limpió con un trapo".

Más allá de la credibilidad del mensaje importa analizar los peligros a los que se enfrentan las mujeres, peligros que nuevamente se mezclan con hechos reales e imaginarios. De ahí que a este tipo de historias se les llame "historias ejemplares" pues pretenden educar mediante el ejemplo sucedido a otros: "Vean lo que les puede suceder si no se cuidan". Implícitamente sugiere que las mujeres no deben andar solas y tener mucho cuidado de cualquier persona, pues ni la gente humilde de cierta edad, y mucho menos si es un hombre, son de fiar.

Por otra parte, el rumor nos recuerda la conocida leyenda urbana del secuestro de jovencitas en los probadores de tiendas departamentales donde se vende ropa femenina, cuyo tema implícito es la trata de blancas. En esa narración se sugería que los comerciantes propietarios de esos establecimientos, generalmente judíos, árabes o libaneses, secuestraban a las jóvenes en los probadores de ropa de sus almacenes para exportarlas a países del Medio Oriente. Dicho rumor circuló a principios de 1969 en Orléans y Amiens, en Francia, y en Barcelona a finales del mismo año (Ortí y Sampere; 2000, Morin, 1969).

En el caso del limpiaparabrisas se dice que llegó en un auto con vidrios polarizados, lo que sugiere un rapto y no un simple robo, como lo sugiere la propia autora anónima del mensaje.

El uso de una sustancia que provoca sueño, mareo o parálisis momentánea en quien lo huele, aunque sea en pequeñas dosis, es un tema recurrente en la literatura policíaca. Las sustancias generalmente puestas en acusación son el éter o el cloroformo, que se han ganado su mala fama como protagonistas de numerosas obras de ficción, ya sea en las salas de operación o como medio de neutralizar al enemigo en operaciones clandestinas y en silencio. Tanto el éter como el cloroformo se han convertido en líquidos "duerme todo" de muchas leyendas contemporáneas, como en el caso de las bebidas adulteradas de los bares, donde los relatos sugieren que los hielos no son de agua, sino de éter, por ejemplo. 
En el siguiente ejemplo, que circuló en noviembre de 2005 en Guadalajara, México, volvemos a encontrar la soporífera sustancia:

C U I D E N S E P O R F A V O R ESTO ESTÁ PASANDO. A una chica la durmieron en el baño de CINEPOLIS y la robaron y ya no recuerda nada, sólo que una Sra. le dio a probar un perfume...

También Yo fui abordada ayer en la tarde cerca de las 3.30 PM en el estacionamiento por dos hombres que me preguntaron cual es el tipo de perfume que yo usaba. Luego, me dijeron si me gustaría probar un tipo de perfume sensacional que ellos estaban vendiendo a un precio de oferta. Probablemente yo habría aceptado si no hubiese recibido este mail algunas semanas atrás.

Los hombres permanecieron entre los autos estacionados, imagino que esperando que alguien más apareciese. Pararon a una señora que iba en dirección de ellos y la previne que me habían avisado que en los centros comerciales o estacionamientos había gente que te abordaba para ofrecerte OLER EL PERFUME que estaban vendiendo pero que en realidad NO es perfume, ES ETER.

Cuando lo hueles te desmayas y aprovechan para robarte todo lo que llevas de valor y solo Dios sabe que más. Envíalo a tus amistades, ya que están operando en todas partes.

Por favor envía esto también a los hombres... Ellos pueden decirle a sus seres queridos.

En esta ocasión se pone el acento en el robo, pero también en "solo Dios sabe qué más", que todos intuimos qué es lo que es. ¿Ladrones armados con somníferos? Nuevamente aparece la mención a centros comerciales y estacionamientos, que además de "no lugares" (sitios de tránsito donde uno es más anónimo y solitario), contraviene la imagen idealizada de los centros comerciales como lugares de compras seguros y familiares. Jan Harold Brunvand nos recuerda que tanto en los nuevos centros comerciales, parques de atracciones o supermercados que se abren, es frecuente escuchar rumores sobre niños a los que se ha intentado secuestrar, lo que la convertiría en una de las leyendas contemporáneas más persistentes (Brunvand, 2002b: 106-109). 
La parte moralista del mensaje sugiere, de forma velada, que esos lugares son peligrosos para las mujeres y no hay que acudir a ellos, al menos solas. No es casual que los lugares incriminados nunca sean los lugares, las plazas y los mercados tradicionales y populares de las ciudades.

En junio de 2002 una versión casi idéntica al mensaje precedente circuló en Buenos Aires. El único cambio era el lugar de los hechos, pues en la versión argentina se citaba el estacionamiento de Wal-mart. Los pequeños cambios de redacción seguramente se deben a las adaptaciones, agregados y distorsiones que van sufriendo los mensajes a lo largo de su camino:

Cuidado con el perfume

Fui abordada ayer a la tarde cerca de las $3.30 \mathrm{pm}$ en el estacionamiento de Walmart por dos hombres que me preguntaron cual es el tipo de perfume que yo usaba. Luego, si me gustaría probar un tipo de perfume sensacional que ellos estaban vendiendo a un precio de oferta. Probablemente yo habría aceptado si no hubiese recibido un mail, algunas semanas atrás, avisádome sobre el golpe del perfume.

Los hombres permanecieron entre los autos estacionados, imagino que esperando que otra mujer apareciese. Paré a una señora que iba en dirección de ellos, y la previne que me habían avisado que en los shoppings o estacionamientos había gente que te abordaba para ofrecerte OLER EL PERFUME que estaban vendiendo pero que NO ES PERFUME. ES ETER.

Cuando lo hueles te desmayas y aprovechan para robarte todo lo que llevas de valor y sólo Dios sabe que mas. Si no hubiese sido por el mail que con el que me avisaron, probablemente hubiese caído en la trampa. Copia este mensaje y envíalo a tus amistades, ya que están operando en todas las ciudades. CUIDENSE ${ }^{8}$

Como último ejemplo de lobo con piel de cordero tenemos el caso de la mujer a quien intentan secuestrar y, posiblemente, asesinar. El motivo que atraviesa los mensajes aquí expuestos es el del maniático urbano, donde la ciudad ha sustituido al campo como terreno de caza del lobo hambriento de carne fresca y femenina.

8 Rompecadenas (http://www.rompecadenas.com.ar/perfume.htm). 
Orale, esto me lo mandaron y esta de mieedooo!!!!!

Creo que hay que tomar todas las precauciones posibles, esto me lo envío una amiga que trabaja en el IDEY, así que esta pasando....Cuidense!!!!!!! Ahora si que lamentablemente hay que tener mucho cuidado!!!

NOTA:ENELESTACIONAMIENTODEPLAZALAS AMERICAS YAHUBOELROBO DE UN VEHICULO DE ESTA MANERA Y EN LAS AFUERAS DE LA GRAN PLAZA HUBO LA VIOLACION DE UNA CHICA CON LAS MISMAS CARACTERISTICAS

Hace aproximadamente un mes se encontraba una mujer a la entrada de un centro comercial distribuyendo volantes a todas las mujeres que pasaban por ahí. La mujer había escrito en el volante una experiencia que tuvo para prevenir a otras tantas. El día anterior esta mujer había terminado sus compras y se dirigió a su carro, descubriendo una llanta ponchada. Sacó el gato de la cajuela para cambiarla. Se acercó un joven señor, vestido con traje, aparentemente todo un ejecutivo portando un portafolio y le preguntó: Noté que trata de cambiar la llanta ponchada, le gustaría que le ayudara? La mujer agradecida aceptó la oferta.

Charlaron cordialmente mientras el hombre cambiaba la llanta, entonces introdujo la llanta ponchada en la cajuela, así como el gato y se sacudió sus manos en señal de que había terminado.

La mujer le agradeció profundamente la ayuda e iba a subir a su carro cuando el hombre le preguntó si podría darle un aventón a su carro que se encontraba al otro lado del centro comercial. Ella se sorprendió y le preguntó porque su carro se encontraba del otro lado. Él le explicó que había quedado en verse con un viejo amigo de ese lado del centro comercial y que había tomado una salida equivocada, motivo por el cual se encontraba de ese lado. La mujer odiaba decirle un "no" después de que tan amablemente la ayudó, pero presintió algo.

Entonces ella recordó haberlo visto meter su portafolio en la cajuela cuando metió la llanta para guardarla. Le contestó que con mucho gusto lo llevaría pero que acababa de recordar que había olvidado comprar algo, que no tardaría, solo le tomaría unos cuantos minutos y que podría aguardarla sentado dentro del carro y que sería lo mas rápida posible. Ella entró nuevamente al centro comercial y le comentó a un guardia de seguridad lo sucedido. 
El guardia salió con ella y se dirigieron a su carro, pero el hombre ya no estaba. Abrieron la cajuela sacó, el portafolio y lo llevó al departamento de policía. El policía lo abrió y cual va siendo su sorpresa cuando encontraron una soga, cinta adhesiva y navajas. Cuando la policía revisó la llanta ponchada, no encontró ninguna ponchadura, simple y sencillamente le sacaron el aire.

Eran obvias las malas intenciones del hombre.

Patricia R., Comunicación social del IDEY

Tel. oficina: $94200 \ldots$

Los relatos sobre maniáticos urbanos nos permiten comprender mejor la persistencia de rumores y leyendas contemporáneas sobre los peligros de la vida moderna. El tema del maniático urbano implica ataques aparentemente inmotivados o irracionales que da golpes al azar y, por tanto, nos convierte a todos en víctimas potenciales. Aunque solemos caracterizar a los demás grupos sociales a partir de su vestimenta y costumbres, nos cuesta mucho más trabajo comprender la personalidad del buen samaritano que, bajo la apariencia de una vida normal y sin problemas, esconde en realidad a un monstruo. Aún más monstruoso en la medida en que aparenta ser normal.

En los relatos anteriores no es casual la presencia de automóviles en relatos con mujeres, que a diferencia de la Pandilla Sangre, protagonizada por hombres, expresa el miedo constante hacia los desconocidos, la locura, lo irracional, la violencia personal, los peligros del viaje y de lo oscuro (los centros comerciales y los estacionamientos suelen ser lugares cerrados, además del automóvil con los vidrios polarizados o el miedo a quedarse dormidas por oler sustancias químicas).

La creencia en este tipo de rumores se basa en las innumerables anécdotas y casos ocurridos en las que una joven trata de ser engañada y logra escapar con un poco de suerte y astucia donde son constantes las seducciones interesadas, las ofertas fraudulentas, pretendidos favores altruistas y secuestros imaginarios. Estos relatos sobre los peligros de la vida moderna y hombres lobo de ciudad se inspiran de microrrelatos que la leyenda urbana organiza y los vuelve significativos a partir de su reelaboración por el público.

Finalmente, encontramos connotaciones bíblicas en los relatos de lobos con piel de cordero que atacan a su víctima (el cordero, símbolo 
de pureza, o la oveja solitaria, símbolo de la oveja descarriada, alejada de las demás, separada del grupo). También encontramos que el pastor (el hombre) se encuentra ausente al momento del ataque. Por lo que la moraleja es que las mujeres no deben estar nunca separadas del rebaño ni fuera de la vista de su guardián. En el fondo se trata de relatos profundamente machistas.

\section{La muerte en directo: las snuff movies}

La expresión en inglés snuff movie (o también snuff films), viene del verbo to snuff que significa "apagar una vela" $\mathrm{y}$, en lenguaje popular, "morir" o "matar". Las snuff movies designan cortometrajes clandestinos, realizados especialmente para ser comercializados para gente rica y perversa donde la actriz, casi siempre una mujer, es torturada y asesinada realmente (Finger, 2001).

Hasta el momento no se ha probado que dichas películas existan o no. Todo aquel que afirma su existencia admite que nunca ha podido ver una, pero "se dice" que existen en el medio de la pornografía extrema. Bien que en ellas no figuran escenas de sexo, las snuff son siempre películas pornográficas en sentido amplio, pues sus consumidores experimentan placer erótico, sádico, al mirar las escenas de tortura y muerte. Su producción es atribuida generalmente a una franja de las películas XXX, próximas a mafias organizadas. Se dice que son realizadas generalmente en América Latina, donde los costos de producción son muy inferiores a los de Estados Unidos, y donde la vida "no vale nada", aunque también se menciona a California, $\mathrm{Ne}$ vada y Nuevo México. Después de la caída de la Cortina de Hierro se señala también a los países de Europa del Este como posibles lugares de filmación.

Algunos especulan sobre la existencia de unas veinte películas de este tipo. Realizadas con fines comerciales, su distribución se realizaría de forma muy discreta y a precio de oro. Algunos dicen que esas películas no están a la venta y se cobra sólo la exhibición, a razón de 200 ó 300 dólares el pase (idem). Las víctimas son con frecuencia mujeres jóvenes raptadas o actrices de porno "ya sin uso". Los verdugos, encargados de torturarlas y darles muerte, son hombres que aparecen con el rostro cubierto por alguna máscara. La decoración 
es mínima: una habitación anónima, una cama o una silla. El arma empleada suele ser un cuchillo, con el que se practican cortes sobre la piel de la víctima y, en consecuencia, hay una gran cantidad de sangre. Las películas son muy cortas, apenas unos cuantos minutos, sin cortes para garantizar la autenticidad, rodadas en video u $8 \mathrm{~mm}$, en blanco y negro, cámara fija, en plano-secuencia y, por supuesto, sin créditos al inicio ni al final.

La fuerza en la creencia sobre las snuff movies era tal que, cuando aparecieron las primeras películas que aprovechaban el rumor, la gente creía verdaderamente que se trataba de películas con secuencias reales, entre ellas Snuff (1976), Hardcore (1978) y Canibal Holocaust (1979). Las investigaciones llevadas a cabo por el FBI, ante las indignadas protestas de grupos conservadores y feministas, no pudieron demostrar nada, salvo que se trataba de hábiles montajes.

A mediados de los años ochenta, una película underground japonesa, titulada Guinea pig: flor de carne y de sangre (1985), de fuerte contenido gore y realismo, muestra a un samurai destazando viva a una joven mujer. Esta película también fue tomada inicialmente como verdadera, e incluso el actor Charlie Sheen contactó al FBI, persuadido de su autenticidad.

A partir de los años ochenta fueron innumerables las películas que explotaron el motivo de las snuff movies: Videodrome (1982), Henry, portrait of a serial killer (1986), Mute Witness (1995), Tesis (1996), The Brave (1997), $8 \mathrm{~mm}$ (1999), La sirène rouge (2002) y otras. En ellas se refuerza el estereotipo de las snuff movies, lo cual ha reforzado la creencia en el fenómeno entre el público, pero también entre aquellos que deberían probar su discernimiento en el ejercicio de su profesión: los policías y los periodistas. Anécdotas no faltan como ilustración: en 1992 llegó a la policía holandesa una fotografía de dos individuos destripados y crucificados con la cabeza hacia abajo. Los expertos científicos de la policía estimaban que se trataba de seres humanos reales y no de maniquíes, y que la foto podía provenir de alguna película. Pero un amante del arte identificó sin problema la foto: se trataba de un cuadro del pintor Franz Van Mieris, expuesto en el Rijksmuseum de Ámsterdam, que representa la ejecución de los hermanos De Witt en La Haya en 1672 (Campion-Vincent y Renard, 2002: 279). 
Como ya ha sido señalado, hasta el momento ninguna snuff movie verdadera ha sido encontrada; aquellas evocadas como reales han demostrado ser hábiles trucajes realizados a partir de las convincentes técnicas del gore. Nunca se ha encontrado un consumidor o un realizador de tales productos. Los testimonios recolectados por las diversas investigaciones son del tipo: "Me dijeron que...", "Parece que...", "Le pasó al amigo de un amigo...", todas expresiones reveladoras del fenómeno del rumor.

La existencia de las snuff movies es poco creíble debido a tres razones: 1) Las snuff son poco rentables desde el punto de vista económico, pues el mercado es muy limitado (al contrario de la droga, la prostitución y el juego) y la ganancia es relativamente poca en comparación con los riesgos que se corren (prisión a perpetuidad o pena de muerte). 2) Hacer un film snuff requiere, si no de una red, al menos de varios cómplices y alguien, en alguna ocasión, hablaría. Finalmente, 3) Los riesgos son muy importantes y para qué molestarse en hacer uno verdadero cuando se pueden hacer de forma que parezcan verdaderos gracias a las sofisticadas técnicas de trucaje, efectos especiales y manipulación de imágenes, cada día más convincentes. Al Goldstein, editor de la revista Screw, lanzó hace ya varios años la oferta de un millón de dólares al primero que llegue con una snuff movie auténtica; el premio sigue sin ser reclamado por nadie (Mikkelson, 1999).

Sin embargo, más interesante es averiguar por qué creemos en la existencia de las snuff movies. Como lo hemos dicho ya en este trabajo, los rumores y las leyendas tienen por origen hechos reales que son extrapolados por el imaginario colectivo. Muertes reales filmadas en directo existen. Con frecuencia se trata de imágenes tomadas por accidente por algún aficionado al momento de espectáculos peligrosos, después de un accidente, durante la realización de un hecho delictuoso $\mathrm{y}$, últimamente, en el caso de los prisioneros ejecutados por sus captores, como en Irak, Afganistán y Chechenia. A partir de esas secuencias las películas de muerte en directo, que pueden incluir secuencias de ejecuciones capitales o torturas, son exhibidas comercialmente, como las series Mondo Cane (1962-1988) y Faces of Death (de 1978 a 1999), así como las recopilaciones hechas por aficionados anónimos que circulan por internet. 
Por otra parte, se ha demostrado que algunos asesinos en serie recuperaban "trofeos" de entre sus víctimas. Unos llegaron a fotografiar o filmar las torturas que infringían, otros mutilaban sus cadáveres, unos pocos más llegaron a grabar en casette los gritos de sus víctimas y, en un par de casos más, filmaron a sus presas, que es el caso de las parejas formadas por Leonard Lake y Charles Ng, en 1985 en Estados Unidos, y de Paul Bernardo y Karla Homolka en 1980 en Canadá (Bourgoin, 1999). En este último caso es cuando nos encontramos muy cerca de las snuff movies, pero en estricto sentido no lo son. Las filmaciones realizadas por los asesinos en serie no muestran la muerte en directo; muestran a la víctima antes o después, y además no hay ninguna intención de comercializar la película.

Las películas de muerte violenta en directo son una forma moderna de un fenómeno social antemporal: la muerte como espectáculo. Desde los días del circo romano, pasando por las ejecuciones públicas de los condenados y los sacrificios humanos, numerosas culturas han respondido a la fascinación del espectáculo de la muerte.

Las ideas que establecen una relación entre la existencia de las snuff movies, las películas pornográficas, los verdugos sádicos y los aficionados perversos se apoyan en una constante antropológica: la asociación del sexo y de la muerte, Eros y Tánatos. El orgasmo como petite mort (pequeña muerte) y las fantasías eróticas de violación y mutilación constituyen un imaginario que se convierte en patológico y criminal una vez pasado el umbral de "no retorno".

La creencia en las snuff movies se apoya en el creciente número y la cada vez mayor audacia de ciertas películas porno y, sobre todo, en las películas sangrientas, llamadas gore o slasher, que confrontan a un asesino loco con jóvenes e inocentes víctimas. Además, la evolución de la técnica ha hecho posible las películas de muerte en directo y, por tanto, hecho verosímil la existencia de las snuff movies. Desde los años sesenta del siglo pasado se han multiplicado las opciones de realización de películas "Hágalo usted mismo": $8 \mathrm{~mm}$, súper 8 , el video, la película Polaroid, el video digital, las cámaras de fotografía digital y las webcams. Ahora todos pueden realizar, con discreción, sus propias películas y fotografías íntimas sin necesidad de revelados complejos y a muy bajos costos. La creencia en la existencia de snuff movies se ha desarrollado 
junto a esta tendencia tecnológica de poner en manos de los aficionados los medios técnicos necesarios y junto a la explosión de la pornografía de manufactura casera.

Nuestras sociedades contemporáneas son cada vez más una civilización de la imagen, una sociedad del espectáculo. La forma extrema de esta tendencia es el voyerismo generalizado: ya no se trata sólo de espiar la vida sexual de los demás, sino su vida completa... hasta la muerte. La televisión, en particular, da un lugar de primera fila a la llamada real TV: docuficciones, video gags, reality shows, Big Brother $\mathrm{y}$ otros tipos de programas que abolen la distinción entre la ficción y la realidad, entre la vida íntima y la vida pública. Finalmente, dicen los enterados, las snuff movies son el único género cinematográfico hecho a partir de la tradición oral.

\section{CONCLUSIONES}

Hemos repasado diversas leyendas urbanas y rumores cuya temática gira en torno a los peligros de la vida moderna. En los ejemplos aquí seleccionados, las víctimas y protagonistas suelen ser las mujeres, quienes de manera simbólica son asociadas a ideales de inocencia, pureza y seres necesitados de protección. Aunque también hemos visto que cualquiera puede ser el blanco de la violencia ciega generalizada.

A medida que las ciudades se han convertido en entramados sociales donde cada vez más se pone de relieve el anonimato, la gente desarrolla y pone en circulación relatos cuyo propósito es anticiparse a las consecuencias negativas y a los peligros que encierran los espacios de tránsito anónimos. Desde este punto de vista, hablamos de "historias ejemplares" a través de las que se pretende educar mediante el ejemplo: "Cuídense, vean lo que les puede pasar". Hechos reales ocurridos, pero inconexos, mezclados junto con los imaginarios, dan origen a este tipo de relatos, que viajan de un punto a otro a través de los medios de comunicación, de boca en boca, por correos electrónicos y páginas de internet.

El estudio de las leyendas urbanas y rumores que circulan a través de la Red son interesantes desde el punto de vista de sus significados simbólicos. En ellos encontramos expresados los miedos de la gente común respecto a los peligros que encierra la vida moderna en las ciu- 
dades y sus temáticas: el miedo al extranjero, al grupo social, a la violencia ciega, a la tecnología y a la agresión sexual. Al mismo tiempo, los relatos contemporáneos de agresión suelen reforzar los estereotipos y prejuicios sociales y poseen una veta moralista y aleccionadora sobre las reglas de convivencia y control social.

A través de esas temáticas, la gente trata de anticiparse al ataque de los bárbaros, bárbaros que ya no asedian los muros de la ciudad sino que se encuentran dentro de ella y desde las sombras preparan su ataque, justo cuando estamos más desprevenidos. Ante este imaginario es que las leyendas urbanas y los rumores expresan con gritos de alerta las angustias de la gente normal, de la vida cotidiana en las ciudades, a través de las cuales accedemos a las enseñanzas morales de la sociedad ("Haz el bien"), a las conductas (agresiones, robos, comportamientos sospechosos) y personajes que deben ser vigilados y castigados (extranjeros y maniáti$\cos$ ), y a la angustia colectiva en un momento dado (atentados terroristas, miedo a enfermedades o la violencia pandilleril). En estos relatos los agresores nunca poseen nombre, ni rostro, son anónimos.

Hemos visto también que junto a la enorme variedad de versiones locales, las leyendas contemporáneas poseen una serie de significados profundos y temáticas bien ancladas en la tradición oral y el folclor popular, que gracias a los contenidos de las industrias culturales es ahora transclasista, ampliamente mediatizado.

Pero no todo es negativo en las leyendas urbanas y en los rumores. Entre las funciones sociales que cumplen encontramos que son informaciones que la gente comparte gustosamente y que sirven para el mantenimiento de las redes sociales y los grupos de pares, pues al intercambiar información que consideramos valiosa (aunque sea falsa o cuestionable), contribuimos al refuerzo de los lazos sociales y al sentimiento de comunidad. También es persistente el deseo de conjurar el mal posible a través del "Por si acaso", que funciona a semejanza de los hechizos y amuletos de antaño para motivar en la gente el sentimiento de que el futuro está aún en sus manos, de que todavía pueden controlar su destino y donde una pequeña ayuda nunca está de más. Desde este punto de vista, es sintomático que muchos correos electrónicos que contienen leyendas urbanas y rumores pidan enviarlo a 3, a 7, a 10 ó a 20 personas más, pues esos números son en cierta forma números ca- 
balísticos, de la buena suerte, que al igual que las patas de conejo o los tréboles de cuatro hojas ayudan a poner la fortuna de nuestro lado.

Finalmente, no es deseable intentar eliminar o controlar las leyendas contemporáneas y los rumores, pues a través de su estudio podemos acceder a las preocupaciones, angustias, reglas de convivencia y motivos de celebración de los grupos sociales en las sociedades contemporáneas.

\section{Bibliografía}

BourgoIn, Stéphane (1999) Serial Killers. Enquête sur les tueurs en série. París: Grasset.

BRUNVAND, Jan Harold (2002a) Encyclopedia of urban legends. Nueva York: W.W. Norton \& Company.

- (2002b) El fabuloso libro de las leyendas urbanas. Demasiado bueno para ser cierto, tomo 2. Barcelona: Alba Editorial.

CAMPION-VINCENT, Véronique y Jean-Bruno Renard (1998) Légendes urbaines. Rumeurs d'aujourd'hui. París: Payot.

- (2002) De source sûre. Nouvelles rumeurs d'aujourd'hui. París: Payot.

CASTORIADIS, Cornelius (1975) La institución imaginaria de la sociedad. Barcelona: Tusquets.

CORTAZAR RODRÍGUEZ, Francisco Javier (2005) "Rumores y leyendas urbanas en internet", Observatorio para la CiberSociedad (http:// www.cibersociedad.net/archivo/articulo.php?art=194).

FINGER, Sarah (2001) La mort en direct, snuff movie. París: Le cherche midi éditeur.

FURIÓ, Vicenç (2000) Sociología del arte. Barcelona: Cátedra.

FUSSEL, Paul (2003) Tiempo de guerra. Conciencia y engaño en la Segunda Guerra Mundial. México: Océano-Turner.

KAPFERER, Jean-Noël (1987) Rumeurs, le plus vieux média du monde. París: Seuil.

MIKKELSON, Barbara (1999) “A Pinch of Snuff”, Snops.com (http:// www.snopes.com/horrors/madmen/snuff.htm).

MORIN, Edgar (1969) La rumeur d'Orléans. París: Seuil.

ORTÍ, Antonio y Joseph Sampere (2000) Leyendas urbanas en España. Barcelona: Martínez Roca. 
PAYNE, Michael (comp.) (2002) Diccionario de teoría crítica y estudios culturales. Buenos Aires: Paidós.

RENARD, Jean-Bruno (1999) Rumeurs et légendes urbaines. París: PUF, Col. Que sais-je ?, núm. 3445.

SONTAG, Susan (1989) La enfermedad y sus metáforas. El sida y sus metáforas. Madrid: Muchnik Editores.

ZIRES ROLDÁN, Margarita (2001) Voz, texto e imagen en interacción. El rumor de los pitufos. México: UAM-X-Porrua.

\section{Recursos en internet}

Hoaxbusters (http:/www.hoaxbuster.com/)

Rompecadenas (http://www.rompecadenas.com.ar/leyendas.htm).

Snopes (www.snopes.com).

The Internet Movie Database (http://uk.imdb.com/). 